Institutional Report

\title{
A Report on the Indian National Centre for Ocean Information Services (INCOIS), Hyderabad
}

S S C SHENOI

Indian National Centre for Ocean Information Services (INCOIS), Hyderabad 500 090, India

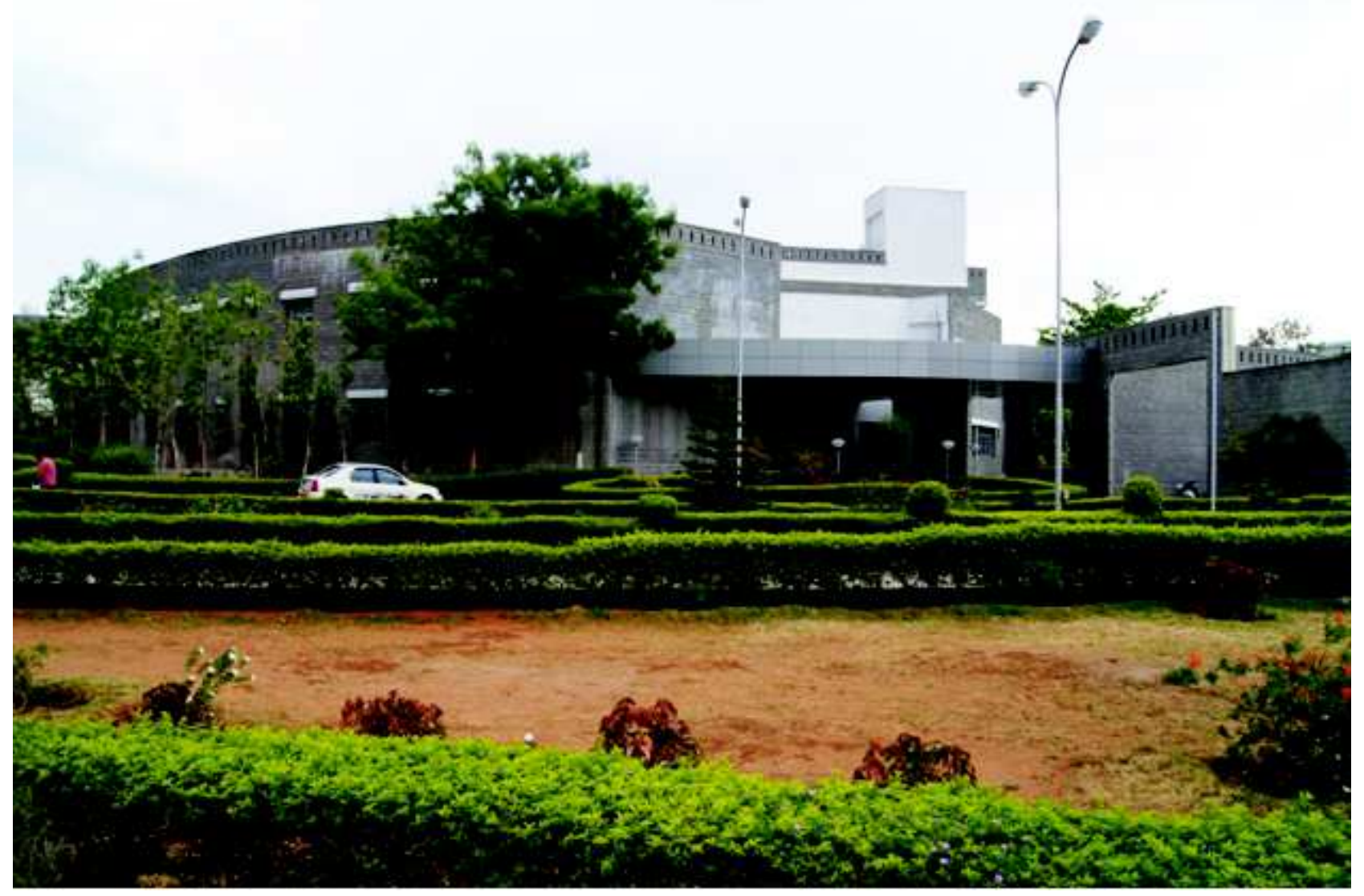

The Indian National Centre for Ocean Information Services (INCOIS) was established in 1999 as an autonomous institution of the erstwhile Department of ocean Development (DOD, presently, the Ministry of Earth Sciences, MoES) to provide ocean information and advisory services tosuch stakeholders as the fishermen, the Indian Navy, CoastGuard, Ports, and Maritime Organizations, coastal population, and offshore resource exploration agencies of the Central and State Governments. INCOISmoved to its Campus in 2005 and developed a forward-looking Road Map of itsVision and Mission for the next decade and beyond.

The vision of INCOIS is to re-position itself as the world leader in providing the operational oceanographic services to the society and become the enabler of the capacity of others through training and research. Accordingly, the mission of INCOIS is "To provide ocean data, information, and advisory

*Author for Correspondence: E-mail: shenoi@incois.gov.in 
services to society, industry, the government and the scientific community through sustained ocean observations and constant improvements through systematic and focused research in information management and ocean modeling."

The spectrum of activities of INCOIS includes:

1. Ocean Information and Advisory Services (Potential Fishing Zoneadvisories, Ocean-State Forecast, Tsunami Early Warnings, Data and Information Services, Coral Bleaching Alerts, Search and Rescue Aid Advisories, prediction of oil spill trajectories, etc.);

2. Ocean Observation Network;

3. Ocean modeling and $\mathrm{R} \& \mathrm{D}$;

4. Web-based Ocean Information Services;

5. Value-added Services and Decision Support Systems;

6. Capacity Development and Training, which includes the International Training Centre for Operational Oceanography, a UNESCO Category 2 Centre.

Since inception, INCOIS has been at the forefront of providing ocean information and advisory services to the fishing community, coastal population, industry, utilities, government, including the defense services and the scientific community through sustained ocean observations and systematic, focused research.

The Potential Fishing Zone (PFZ) Advisory was the first service started by INCOIS and has remained as one of its flagship programme. Over theyears, the technology for the generation of PFZ information, as well as the modes of dissemination of the advisories, has evolved a great deal leading to more accurate warnings in a shorter timeframe to a broader reach of the community. Concurrently with the innovations in the generation and dissemination of the PFZ advisories, INCOIS has also partnered with the various stakeholders and NGOs to educate the fishermen and to assist them in understanding the advisories for effective downstream dissemination of the knowledge. While endeavoring to sustain this program, INCOIS also continuously improved on the advisories through the adoption of state-of-the-art technologies for data acquisition, processing, modeling and dissemination. At present, more than 6.75 lakh active fishermen are receiving the PFZ advisories on their mobiles through SMS directly from INCOIS. The number of fishermen who receive the PFZ advisories through other channels like local radios, electronic display boards and village information centers operated by NGOs is in addition to the number above.Soon INCOIS will be forecasting the PFZ forthe next three days using numerical models.

Under the Ocean State Forecast services, INCOIS provides forecasts on wave height, direction and period (of both wind waves and swell waves), Sea Surface Currents, Sea Surface Temperature, Mixed Layer Depth, Depth of thermocline, Astronomical tides, Wind speed and direction, Oilspill trajectories (when they occurred), Search and Rescue aid, etc. The Forecasts are generated through a suite ofstate-of-the-art numericalmodels, which are evaluated extensively using observations from realtime observational systems. The User feedbacks suggest that the forecasts are accurate (at least 80\% of the time) and they reach the end-users (fishermen, navigators, ports and harbors, Indian Navy, Coast Guard, etc.) and the Disaster Management Authorities on time.

The Global Ocean reanalysis generated daily by assimilating the observations in the ocean general circulation model are provided regularly to IITM,Pune, NCMRWF, New Delhi and IMD, New Delhi. The ocean reanalysis is used to prescribe theinitial condition for atmospheric models. They are also used as the boundary conditions for the regional models used for the generation ofocean state forecasts at INCOIS.

The Tsunami Early Warning System at INCOIS comprises a real-time network ofseismic stations, tsunami buoys, tide gauges, and a 247 operational Warning Centre todetect tsunamigenic earthquakes, to monitor tsunamis and to provide timely advisoriesto the vulnerable community and the disaster management agencies. The Warning Centre is capable of issuing Tsunami bulletins in less than 10 minutes after any significant earthquake in the Indian Ocean, thus responding/lead time of about 10- 20 minutes for near-source regions and a few hours in the case of far source regions. Currently, the Warning Centre disseminates tsunami advisories to various stakeholders through multiple dissemination modes 


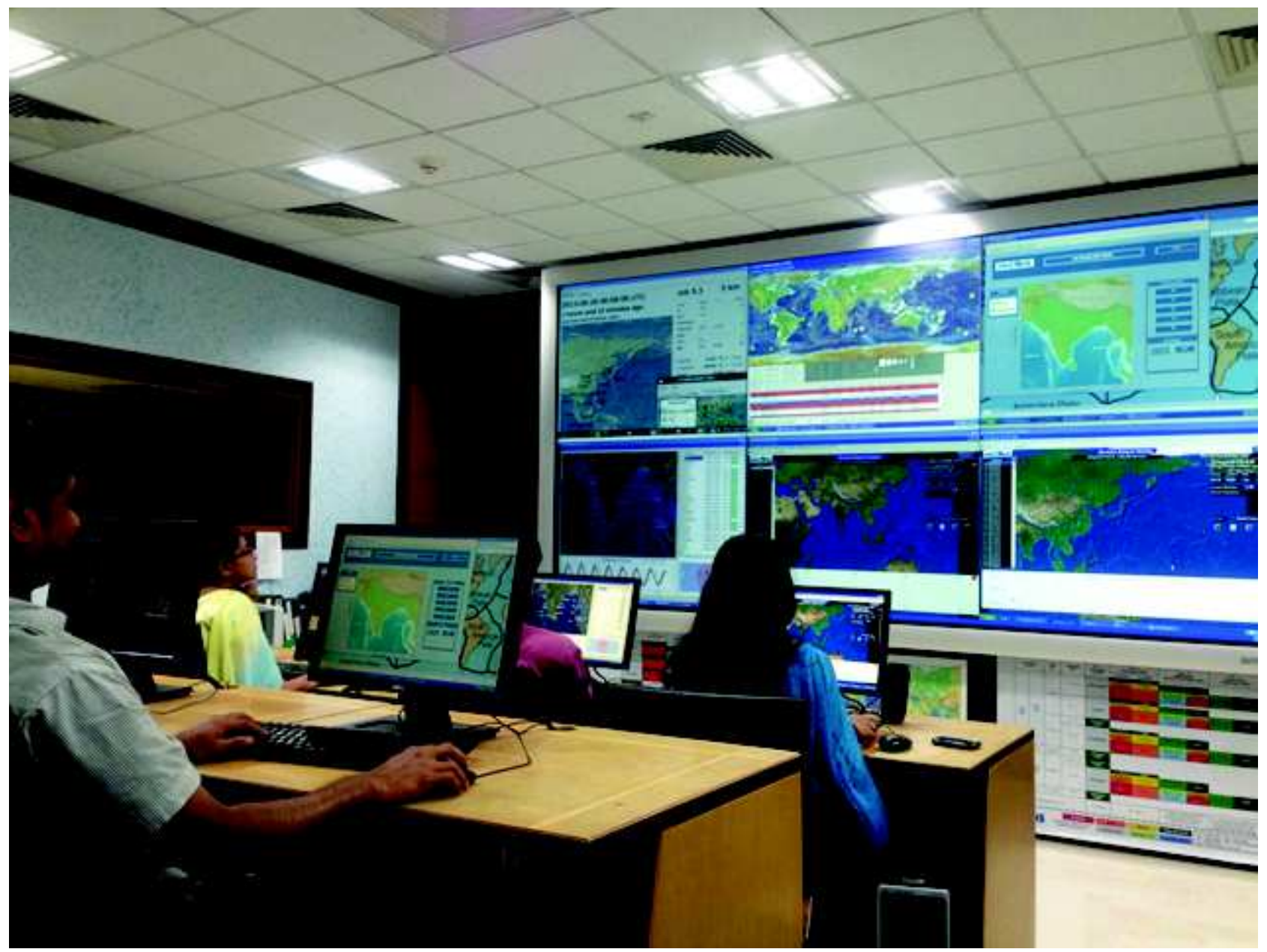

simultaneously (Fax, Phone, Emails, GTS and SMS etc.). Since October 2012, the Inter-governmental Oceanographic Commission (IOC) of UNESCO has designated the Indian Tsunami Early Centre as the tsunami warning serviceprovider for the 23 countries on the Indian Ocean rim. Since then, INCOIS is serving as the National Tsunami Early Warning Centre for India and also as the Regional Tsunami Service Provider (RTSP) for all countries on the Indian Ocean rim. Having completed the creation of the high accuracy topographic maps of the entire coast with the help of NRSC, Hyderabad, the tsunami model also has been modified to provide the level and extent of inundation in the coastal villages, towns, and cities which will aid in focused and efficient disaster management.

On the Ocean Observations front, INCOIS collaborates with several national and international institutions in the deployment and maintenance of a host of ocean facilities such as moored met-ocean data buoys, XBTs and XCTDs, ARGO floats, waverider buoys, AWSs, ADCP network, BPRs etc. to acquire real-time in-situ oceanographic and nearsurface meteorological data. These in-situ observation networks have been providing near/real-time metocean data in different spatiotemporal scales from the Indian Ocean region. INCOIS as well as the weather forecasting centers, assimilate these observations, in real-time, in the ocean state and weather forecasting models. The data are further used for the validation of models, research on ocean processes and their variability and for monitoring the changes in ocean parameters due to the changing climate. Recently, many of these platforms and facilities got upgraded and augmented. A buoy has been equipped with several sophisticated sensors to make a direct measurement of air-sea fluxes, and the upper ocean structure is deployed in the Bay of Bengal on 22 May 2019. This data willhelp in estimating the 
errors in air-sea fluxes. Theerrors in air-sea fluxes could be one of the major reasons for the errors in weather prediction models, especially in the seasonal forecasts like a monsoon.

The National Oceanographic Data Centre at INCOIS archives the data gathered and disseminates that to the relevant stakeholders. The Digital Ocean at INCOIS integrate all types of data on a single digital platform and enables simultaneous visualization of all allied data at one go.

The Ocean modeling and $\mathbf{R} \& \mathbf{D}$ at INCOIS focuses on understanding the processes in the ocean and the development of numerical models used for the generation of operational ocean forecasts/analysis/ reanalysis. Over 415 scientific publications from INCOIS since 2002 in reputed national and international journals indicate the research caliber of INCOIS.

On the capacity development and training front, the International Training Centre for Operational Oceanography (ITCOocean), a UNESCO Category 2 Centre, provides advanced training in operational oceanography for young scientists and technical persons and decision-makers/ officials from India, the IOR countries and other developing nations. Since its inception in 2013, the ITCO ocean has conducted 43 Training Courses and trained about 1150 personnel of which 325 were from 36 different countries.

A new project, aiming at Coastal Monitoring and prediction, monitors the physical and biogeochemical parameters of waters around India at 6 locations using autonomous instruments and utilize that data to nowcast and forecast the water quality regularly. The project is named Marine Observation System Along Indian Coast (MOSAIC).

The initiatives and concerted efforts of INCOIS have resulted in India achieving a leadership role in Ocean Observations and forecasting services in the Indian Ocean region culminated in India playing an active and dominant position in several international for a of the ocean realm such as the ARGO, IOGOOS, IOC/IOTWS, IODE, IIOE-2, POGO, SIBER, IAPSO/IUGG, UCDI/IUGG, etc.

The success of INCOIS is evident from the socio-economic benefits of the services provided by INCOIS. The studies carried out by the National Council for Applied Economic Research (NCAER), New Delhi in 2010 and 2015 pointed out the economic benefits reaped by the stakeholders. As per their Assessment, the economic benefits due to the identification of PFZ advisories ranges between Rs. 34000 to 50000 and the savings due to the timely usage of ocean state forecasts and tsunami early warnings by various stakeholders are in the range of trillion Rupees.

While the three primary services, PFZ advisories, Ocean State Forecasts and Tsunami Early Warnings, provided by INCOIS serve the public goods, later two also serves the strategic products of the country by way of protecting its citizen from natural calamities and advising the Indian Navy and Coast Guard, on the conditions of ocean, when they want to conduct their activities. In the coming years, as the country's emphasis shifts towards the Blue Economy, the demands on the ocean information and forecasting services are sure to rise unprecedentedly. Hence, it is necessary to nurture the activities at INCOIS well. 